\title{
Avaliação do produção e da qualidade bacteriológica e detecção de bacteriófagos e de antimicrobianos em soro de queijo produzido no estado do Rio de Janeiro*
}

\section{Evaluation of production and bacteriological quality and detection of bacteriophages and antimicrobial agents in cheese whey produced in Rio de Janeiro state}

\author{
Neila Mello Santos Cortez, ${ }^{* *}$ Flávia Aline Andrade Calixto, ${ }^{* *}$ Oriel Fajardo de Campos, ${ }^{* * *}$ Rosangela Zoccal, ${ }^{* * * *}$ \\ Robson Maia Franco, ${ }^{* * * *}$ Marco Antonio Sloboda Cortez ${ }^{* * * * *}$
}

\begin{abstract}
Resumo
O objetivo do trabalho foi avaliar a qualidade do soro por meio da contagem de micro-organismos mesófilos, psicrotróficos e enumeração de coliformes e da detecção de bacteriófagos e antimicrobianos. Para verificar a qualidade e o uso do soro juntamente com a coleta, foi aplicado um questionário em 50 estabelecimentos processadores de leite e derivados fiscalizados no Estado do Rio de Janeiro. De todo soro produzido (4.114 toneladas) 30,76\% é aproveitado na produção de derivados lácteos, $29,18 \%$ é enviado para Minas Gerais, 7,18\% vendido, 32,88\% distribuído para alimentação animal. Somente nove estabelecimentos realizam programa de controle de qualidade. A avaliação bacteriológica apresentou $86,36 \%$ de bactérias psicrotróficas acima do valor permitido por lei, $36 \%$ amostras positivas para antimicrobianos e negatividade para bacteriófagos. Na colimetria os coliformes a $35^{\circ} \mathrm{C}$ apresentou em $60 \%$ das amostras valor médio de $2,8 \times 10^{4} \mathrm{NMP} / \mathrm{mL}$, os coliformes a $45^{\circ} \mathrm{C}$ com valor médio de $2,5 \times 10^{4}$ NMP / mL e encontrado Escherichia coli em $30 \%$ das amostras. A ausência de fago é um ponto positivo para as indústrias, assim como o aproveitamento parcial do soro. A presença de antimicrobianos é considerada um risco saúde do consumidor.
\end{abstract}

Palavras-chave: soro de queijo, qualidade microbiológica, antibiótico, fagos.

\begin{abstract}
The objective of this study was to evaluate cheese whey quality regards to mesophilic, psychrotrophic and coliforms bacteria, bacteriophages and antimicrobial substances detection. The samples were collected from 50 dairy industries in Rio de Janeiro state and a questionnaire was carried out. Of total whey produced, $30.7 \%$ were utilized to dairy products production, and $42.15 \%$ were concentrated and sent to Minas Gerais state, $10.37 \%$ were sold and $47.48 \%$ distributed to animal feed. Bacteriological evaluation showed high count of psychrotrophic bacteria (86.36\%). Seventeen samples (36\%) were positive to antimicrobial analysis. The search of bacteriophages was negative to all samples. Relative to $35^{\circ} \mathrm{C}$ colimetric counts, $40 \%$ of samples presented more than $1.1 \times 10^{4} \mathrm{NMP} / \mathrm{mL}$ and $60 \%$ of samples presented $2.8 \times 10^{4} \mathrm{NMP} / \mathrm{mL}$. The coliforms $45^{\circ} \mathrm{C}$ counts were $2.5 \times 10^{4} \mathrm{NMP} / \mathrm{mL}$ and it was found Escherichia coli in $30 \%$ of samples. The absence of phage was a positive point to industries as well as the rational use of whey, however the presence of antimicrobial agents could be considered a risk to the consumer.
\end{abstract}

Keywords: cheese whey, microbiological quality, antibiotics, phages

\section{Introdução}

O soro de leite é o líquido formado a partir da coagulação das caseínas do leite, considerado um subproduto, correspondendo cerca de $90 \%$ do volume inicial do leite, perfazendo de 50 a $55 \%$ dos sólidos totais do mesmo (Furtado e Lourenço Neto, 1994; Antunes, 2003).
Nas indústrias, este produto apresenta valor comercial baixo quando in natura e apresenta alto custo de captação, normalmente tratado como dejeto e lançado nos cursos dos rios sem tratamento prévio, sendo um poluente ambiental aumentando a demanda bioquímica de oxigênio (Chehadi, 2004; Barbosa et al., 2010). Com o uso da tecnologia de membranas

\footnotetext{
${ }^{*}$ Recebido em 16 de maio de 2013 e aceito em 13 de agosto de 2013.

${ }^{* *}$ Curso de Pós-Graduação em Higiene Veterinária e Processamento Tecnológico em Produtos de Origem Animal - Universidade Federal Fluminense. Rua Vital Brazil Filho 64 - cep: 24230-340 - Vital Brazil - Niterói - RJ. neilacortez@yahoo.com.br, faacalixto@yahoo.com.br

***Embrapa Gado de Leite, Engenheiro Agrônomo. PhD Michigan State University. Rua Espírito Santos, 196/706 Juiz de Fora/MG. orielfajardo@ig.com.br

****Embrapa Gado de Leite. Pesquisadora. Rua Espírito Santos, 196/706 Juiz de Fora/MG. rosangelazoccal@embrapa.br

${ }^{\star * \star \star *}$ Departamento de Tecnologia de Alimentos - Faculdade de veterinária - Universidade Federal Fluminense. Rua Vital Brazil Filho 64 - cep: $24230-340$ - Vital Brazil - Niterói - RJ. robsonmf@vm.uff.br, masc1971@yahoo.com.br
} 
as indústrias de laticínios conseguem uma alta redução dos contaminantes do soro antes do mesmo ser despejado nos rios.

A composição do soro, rico em lactose e outros nutrientes solúveis, propiciam o crescimento de diversos micro-organismos que ocasionam alterações sensoriais e químicas, além de estarem associados a riscos para a saúde coletiva devido à presença de micro-organismos patogênicos (Fox et al., 2000; Bonfoh et al., 2003).

A contaminação por micro-organismo do grupo coliforme acarreta em alterações nas características sensoriais, como sabor ácido e estufamento precoce com produção de gás carbônico e ácido acético, além de ocasionar visualmente ao queijo uma distribuição de olhaduras irregulares (Shneider, 2009).

Além dos contaminantes deteriorantes, o soro é passível de fonte de bacteriófagos (fagos), que age como fator de contaminação em lacticínios na fabricação de queijos e leites fermentados diminuindo a viabilidade das bactérias ácido-láticas. (Nader Filho et al., 2004; Lima et al., 2009).

Os bacteriófagos são vírus que infectam bactérias; são parasitas intracelulares obrigatórios, não possuindo metabolismo próprio (Zink e Loessner, 1992).

Uma vez tendo surgido, os fagos podem se espalhar rapidamente em todo o laticínio. Sua presença é de difícil eliminação devido ao curto período de latência, e por serem resistentes à pasteurização (Madera et al., 2004). Estima-se que de $60-70 \%$ da ocorrência de problemas tecnológicos na fabricação de queijos estejam relacionados com infecção por bacteriófagos das cepas de Lactobacillus (Hejnowicz e Bardowski, 2005).

A presença de resíduos de antimicrobianos no leite, utilizadas nas várias etapas de produção animal, tem sido um dos maiores desafios impostos à indústria de alimentos no mundo, como a interferência no processo de produção dos derivados, como a inibição das culturas lácticas (Nader Filho et al., 2004; Tenório 2009).

A ingestão de resíduos de antibióticos presentes nos alimentos supõe risco para a saúde humana, seja exercendo pressão seletiva sobre a microbiota intestinal, favorecendo o crescimento de micro-organismos com resistência natural ou adquirida, ou dando lugar, direta ou indiretamente, para o aparecimento de resistência em bactérias enteropatogênicas, possíveis casos de reações alérgicas e efeitos teratogênicos (Costa et al., 1996; Van Schaik et al., 2002; Shitandi e kihumbu, 2004;)

Mesmo após o tratamento térmico do leite, o mesmo pode apresentar resíduos de antibióticos e consequentemente em todas as etapas na elaboração de queijos e o subproduto (soro) podem veicular esses antimicrobianos (Brito, 2000).

O objetivo desta pesquisa foi avaliar a quantidade do soro produzido no Estado do Rio de Janeiro e a qualidade a partir da contagem dos micro-organismos mesófilos e psicrotróficos, da enumeração dos coliformes $\left(30 / 35^{\circ} \mathrm{C}\right.$ e $\left.45^{\circ} \mathrm{C}\right)$, da detecção de bacteriófagos e de substâncias antimicrobianas.

\section{Material e métodos}

Foi realizado um levantamento das indústrias fiscalizadas ou não no Estado do Rio de Janeiro pela EMATER (órgão estadual de Extensão Rural do Rio de Janeiro) totalizando um número de 50 estabelecimentos. Em seguida, foi traçada uma divisão do estado em cinco regiões (Noroeste, Serrana, Norte, Centro e Sul).

A fim de concentrar os dados, as coletas das amostras eram feitas por região e um questionário era aplicado sobre a produção e uso do soro de leite na indústria.

Em cada indústria eram coletados três frascos estéreis, de $300 \mathrm{~mL}$, sendo transportado em caixas isotérmicas contendo gelo reciclável para os Laboratórios de Leite e Derivados e de Controle Microbiológico de Produtos de Origem Animal da Faculdade de Veterinária da Universidade Federal Fluminense em até 24 horas após a coleta para análises bacteriológicas.

A partir das amostras coletadas foram realizadas diluições seriadas em Solução Salina Peptonada (SSP 0,1\%). Para a contagem de bactérias heterotróficas aeróbias mesófilas e psicrotróficas American Public Health Association (2001). Foi realizada a técnica de plaqueamento em profundidade com o meio para contagem padrão em placas (APC). Para a pesquisa de mesófilos as placas foram colocadas em estufa de $35^{\circ} \mathrm{C}$ por $24 / 48$ horas e para os psicrotróficos foram armazenadas em geladeira $\left(6 \pm 1^{\circ} \mathrm{C}\right.$ por 10 dias). Depois deste prazo as placas foram removidas e selecionadas aquelas que apresentarem entre 30-300 Unidades Formadoras de Colônias (UFC) para contagem. O resultado foi expresso em log10 UFCs/g.

Na enumeração de Coliformes foi utilizada a técnica do Número Mais Provável (NMP) conforme Merck (2002) modificado por Franco e Mantilla (2005). A técnica consiste na miniaturização das diluições com SSP $(0,1 \%)$ e do caldo Fluorocult Merck para a enumeração. Os ependorfes foram incubados a $35{ }^{\circ} \mathrm{C}$ por 24 horas. Os resultados positivos para Coliformes Totais foram verificados a partir da observação de coloração azul. Os ependorfes positivos com ação direta de Luz Ultravioleta, que fluorescessem confirmava a presença de Coliformes Fecais. Nos ependorfes positivos para Coliformes Fecais eram adicionadas 1 a 2 gotas de reativo de Kovac's e os que tiveram viragem vermelha confirmava Escherichia coli.

A detecção de resíduos de antibióticos e antimicrobianos foi feita pelo Kit enzimático Eclipse da Empresa Cap-Lab. A coloração azul da amostra teste confirmava positividade; se cor amarela na amostra, o resultado era negativo. A formação de um halo azul na borda significava uso de antibiótico dentro do limite permitido.

Para a pesquisa de fagos foram realizadas duas técnicas: uma para presença e outra para o isolamento de bacteriófago, a partir de métodos descritos por Fox et al. (2000). Na técnica em tubos, o soro foi filtrado em membrana e utilizados tubos com $10 \mathrm{~mL}$ da cultura láctea $\left(10^{8} \mathrm{ufc} / \mathrm{mL}\right)$ e colocados em estufas de $35^{\circ} \mathrm{e}$ $42^{\circ} \mathrm{C}$. Foi determinado o $\mathrm{pH}$ de hora em hora. A diferença de 0,3 unidades da amostra controle e da amostra em análise representa a presença de fago na amostra em estudo. Na técnica em placas, para o isolamento do fago, foi realizada filtração da amostra $10^{\circ}$ (amostra sem a diluição) seguida das diluições $\left(10^{-1}, 10^{-2} ; 10^{-3}\right.$; $10^{-4}$ e $\left.10^{-5}\right)$. Em seguida vazada em placas com o meio Ágar base MRS e adicionado mais o meio com a mistura $(0,7 \%$ Ágar + Caldo $\left.\mathrm{MRS}+\mathrm{CaCl}_{2}\right)$ e $1 \mathrm{~mL}$ de suspensão bacteriana da cultura $\left(10^{8}\right.$ ufc/mL). Incubado em estufas de $35^{\circ}$ e $42^{\circ} \mathrm{C}$ durante 24 horas. A presença dos halos de lise confirma a presença de fago.

A análise estatística descritiva foi realizada utilizando-se o programa GraphPad Prism version 5.00 for Windows (GraphPad Software, San Diego California USA). 


\section{Resultados e discussão}

Das pesquisas realizadas nos estabelecimentos produtores de soro de leite, das 4.114 toneladas de soro gerados por mês, 30,7\% (1.267 toneladas) é aproveitada industrialmente na produção de ricota $(78 \%)$, bebida láctea UHT $(18 \%)$ ou bebida láctea fermentada (4\%), o que mostra um baixo valor na demanda de produtos à base de soro.

O restante do soro produzido -2.847 toneladas por mês $(69,3 \%)$ possuía outros destinos como: enviado para Minas Gerais após concentração $(42,15 \%)$, vendido $(10,37 \%)$ ou distribuídas gratuitamente para cooperados ou fazendeiros próximos $(47,48 \%)$ para alimentação animal (bovinos e suínos).

A maioria das indústrias (41,3\%) estava sob inspeção estadual, das quais $23,1 \%$ sob inspeção federal e o mesmo percentual sob inspeção municipal, o que garantia uma segurança maior aos produtos elaborados assim como o soro produzido na indústria (Figura 1). Praticamente $10 \%$ delas não estavam sob inspeção técnica, problema de saúde pública. Somente nove $(17,3 \%)$ afirmaram adotar algum Programa de Controle de Qualidade (Boas Práticas de Fabricação, Procedimento Padrão de Higiene Operacional e Análises de Perigos e Pontos Críticos de Controle), o que provavelmente gera deficiência na produção e qualidade nos produtos e derivados de leite.
Em relação à contagem total de bactérias e colimetria, as amostras apresentaram valores bem distintos. A Tabela 1 lista os valores bacteriológicos pesquisados nos 50 estabelecimentos produtores de soro de leite (em log UFC/mL).

A elevada contaminação bacteriológica de algumas amostras de soro, inclusive com bactérias patogênicas ( $E$. coli), pode estar relacionada com um processo de fabricação de queijo sem condições de higiene, o que refletiu na presença destes micro-organismos no soro (Cortez; Cortez, 2010). A contagem de psicrotróficos foi $86,36 \%$ da contagem de mesófilos.

A contaminação microbiológica do subproduto soro acarreta sérios problemas aos derivados que contêm soro de queijo (Siso, 1996).

A contagem de psicrotróficos é preconizada pelo Ministério de Agricultura, Pecuária e Abastecimento (Brasil, 2008) um valor máximo de $10 \%$ acima do padrão de mesófilos.

O trabalho apresentou um valor médio de psicrotróficos (17.742.764 UFC/mL) que foi aproximadamente $44,5 \%$ da contagem média de mesófilos (39.775.347 UFC/mL) o que significa evidente problema de higienização. No trabalho de Teixeira et al. (2007) com soro de leite, a contagem de psicrotróficos apresentou em $32,9 \%$ das amostras um valor entre $2,6 \times 10 \mathrm{e}$ $3,4 \times 10 \mathrm{NMP} / \mathrm{mL}$ padrão inferior ao do discutido no trabalho $(1,0$ $x 10^{3}$ a $\left.4,2 \times 10^{8} \mathrm{NMP} / \mathrm{mL}\right)$. Em consequência, a elaboração de produtos derivados de soro poderá ser comprometida.

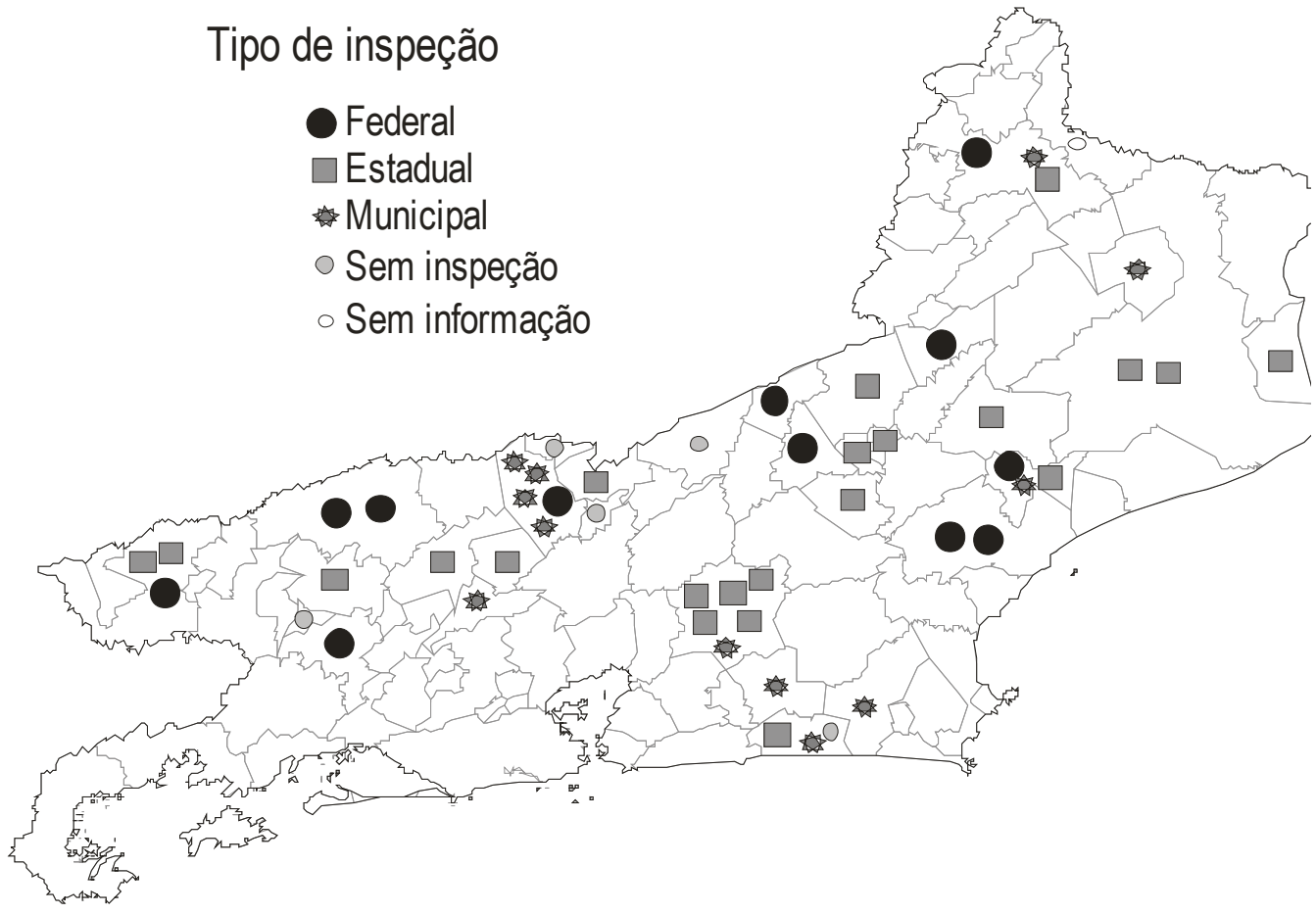

Figura 1: Sistemas de inspeção (Municipal, Estadual e Federal) nos laticínios do Estado do Rio de Janeiro, em 2009.

Siso (1996) relatou que $50 \%$ da produção mundial de soro foi tratada e transformada em vários produtos alimentares, sendo que deste total quase a metade foi usada diretamente na forma líquida. O restante do soro tem vários outros destinos como o descarte sem tratamento prévio nos cursos de rios e córregos ou alimentação animal.
Poucos são os trabalhos que avaliaram a microbiota do soro (Teixeira et al., 2007. Em contrapartida, vários relatam contaminação de deteriorantes e patogênicos em variados tipos de queijos (Campos et al., 2006; Zaffari et al., 2007; Shneider, 2009; Santos e Hoffmann, 2010). Quanto à qualidade microbiológica, o soro pode ser um produto de curto prazo de validade devido ao elevado valor nutritivo, às condições de umidade e ao $\mathrm{pH}$, que são favoráveis ao crescimento microbiano (Chiappini et al. 1995).

Vale ressaltar que o leite que apresenta uma alta carga microbiana pode levar aos derivados essa contaminação, como no soro também. Outro ponto a ser considerado é a utilização de bactérias láticas como culturas primárias e secundárias na fabricação dos diversos queijos, o que implica a produção de um soro já contaminado. Estes fatores associados explicam e justificam a necessidade de realizar uma triagem ou uma verificação das condições microbiológicas do soro antes de utilizá-lo para a elaboração de qualquer derivado lácteo, sob risco de redução da segurança, qualidade e do prazo de validade do mesmo. 
Tabela 1: Valores de média, mínimo, máximo e desvio padrão da contagem de mesófilos e psicrotróficos e enumeração dos coliformes do soro de queijo produzido no Estado do Rio de Janeiro

\begin{tabular}{|c|c|c|c|c|c|}
\hline LATICÍNIOS & Mesófilos & Psicrotróficos & Coliformes $30^{\circ} / 35^{\circ} \mathrm{C}$ & Coliforme $45^{\circ} \mathrm{C}$ & Escherichia coli \\
\hline 1 & 8,38 & 6,61 & * & 0 & 0 \\
\hline 2 & 8,23 & 6,04 & * & 0 & 0 \\
\hline 3 & 7,26 & 7,69 & * & 0 & 0 \\
\hline 4 & 8,26 & 7,00 & * & 0 & 0 \\
\hline 5 & 5,51 & 3,48 & 2,85 & 0 & 0 \\
\hline 6 & 6,80 & 7,32 & 5,08 & 0 & 0 \\
\hline 7 & 7,41 & 6,28 & 4,38 & 2,85 & 0 \\
\hline 8 & 5,23 & 8,00 & 4,18 & 2,97 & 2,48 \\
\hline 9 & 5,08 & 8,11 & 3,28 & 0 & 0 \\
\hline 10 & 6,20 & 8,62 & 3,18 & 2,85 & 2,48 \\
\hline 11 & 6,08 & 6,53 & 2,85 & 0 & 0 \\
\hline 12 & 5,45 & 7,95 & 4,32 & 2,79 & 2,48 \\
\hline 13 & 6,88 & 4,74 & * & 0 & 0 \\
\hline 14 & 7,00 & 5,26 & * & 0 & 0 \\
\hline 15 & 5,34 & 5,26 & 3,85 & 0 & 0 \\
\hline 16 & 8,26 & 4,70 & * & 6,04 & 4,30 \\
\hline 17 & 6,23 & 5,30 & 3,36 & 0 & 0 \\
\hline 18 & 8,88 & 4,80 & 3,18 & 0 & 0 \\
\hline 19 & 5,28 & 4,08 & 2,60 & 0 & 0 \\
\hline 20 & 6,40 & 3,70 & 3,18 & 2,95 & 0 \\
\hline 21 & 5,63 & 4,88 & 4,38 & 2,85 & 0 \\
\hline 22 & 4,00 & 4,83 & 2,95 & 0 & 0 \\
\hline 23 & 5,15 & 4,48 & 3,97 & 0 & 0 \\
\hline 24 & 4,30 & 3,48 & 2,60 & 0 & 0 \\
\hline 25 & 5,60 & 5,18 & 3,97 & 2,60 & 0 \\
\hline 26 & 4,83 & 4,36 & 4,38 & 0 & 0 \\
\hline 27 & 5,72 & 5,12 & 2,60 & 0 & 0 \\
\hline 28 & 5,83 & 5,93 & 5,04 & 2,48 & 2,48 \\
\hline 29 & 5,51 & 5,08 & 2,85 & 0 & 0 \\
\hline 30 & 5,18 & 4,68 & 2,85 & 0 & 0 \\
\hline 31 & 6,46 & 4,43 & 4,66 & 0 & 0 \\
\hline 32 & 7,26 & 5,71 & 4,04 & 4,66 & 3,32 \\
\hline 33 & 8,40 & 7,28 & * & 0 & 0 \\
\hline 34 & 5,95 & 7,45 & * & 0 & 0 \\
\hline 35 & 6,11 & 4,36 & * & 4,04 & 3,32 \\
\hline 36 & 5,95 & 4,60 & * & 4,04 & 3,45 \\
\hline 37 & 6,20 & 5,26 & * & 0 & 0 \\
\hline 38 & 5,93 & 6,11 & * & 3,97 & 3,18 \\
\hline 39 & 5,86 & 5,45 & * & 3,97 & 3,97 \\
\hline 40 & 7,20 & 4,00 & * & 4,18 & 3,32 \\
\hline 41 & 4,30 & 3,08 & 3,63 & 0 & 0 \\
\hline 42 & 7,41 & 3,30 & * & 0 & 0 \\
\hline 43 & 7,26 & 6,38 & * & 3,18 & 2,60 \\
\hline 44 & $* *$ & 6,40 & * & 0 & 0 \\
\hline 45 & 4,00 & 4,04 & 2,95 & 0 & 0 \\
\hline 46 & 6,62 & 4,40 & * & 2,60 & 2,60 \\
\hline 47 & 4,54 & 3,00 & 3,30 & 2,95 & 2,95 \\
\hline 48 & 6,92 & 4,89 & * & 3,63 & 3,63 \\
\hline 49 & 4,48 & 3,00 & 3,04 & 0 & 0 \\
\hline 50 & 5,45 & 3,60 & 2,85 & 0 & 0 \\
\hline Média & 6,16 & 5,32 & 4,54 & 1,31 & 0,93 \\
\hline Valor Mínimo & 4,00 & 3,00 & 2,60 & 0,00 & 0,00 \\
\hline Valor Máximo & 8,88 & 8,62 & 6,04 & 6,04 & 4,30 \\
\hline Desvio-padrão & 1,22 & 1,47 & 1,36 & 1,78 & 1,47 \\
\hline
\end{tabular}


Na pesquisa de Santos e Hoffmann (2010) para a determinação de coliformes $30^{\circ} / 35^{\circ} \mathrm{C}$, observou-se valor médio de $6,3 \times 10^{2}$ $\mathrm{NMP} / \mathrm{mL}$, coliformes $45^{\circ} \mathrm{C}$ de $2,7 \times 10^{1} \mathrm{NMP} / \mathrm{mL}$ e a presença de Escherichia coli em 33,3\% das amostras. No estudo em questão, a pesquisa de coliformes $35^{\circ} \mathrm{C}$ e a $45^{\circ} \mathrm{C}$ apresentaram valores superiores e semelhança com a pesquisa de $E$. coli com $30 \%$ de presença.

No estudo de Teixeira et al. (2007) $58,4 \%$ das amostras apresentaram valor de $2,4 \times 10^{1}$ para coliformes a $30^{\circ} / 35^{\circ} \mathrm{Ce} 1,1$ x $10^{1}$ para coliformes a $45^{\circ} \mathrm{C}$ no soro de queijo Minas Frescal, médias inferiores ao avaliado no trabalho.

No trabalho conduzido por Campos e colaboradores (2006), um elevado percentual de amostras de queijo Minas Frescal apresentou E. coli, gerando preocupação, em virtude do risco potencial de causar enfermidades.

Na avaliação microbiológica (coliformes, Listeria spp. e Brucella spp.) de 80 queijos artesanais, o trabalho realizado por Zaffari e colaboradores (2007), apresentou como resultado todas as amostras positivas para coliformes totais, $84 \%$ das amostras com presença de coliformes fecais acima do permitido por lei que revela que o consumo destes queijos constitui perigo de infecção à população em geral.

Em pesquisa com queijos Serrano, na detecção e enumeração de coliformes a $45^{\circ} \mathrm{C}$ três queijos foram considerados impróprios para o consumo humano. A contagem de coliformes ficou acima do permitido por lei (Shneider, 2009).

As amostras de soro apresentaram negatividade na presença de bacteriófagos, o que é um fato positivo para as indústrias produtoras. Esse resultado negativo possivelmente se deve à cultura láctea utilizada nas análises, sendo as mesmas resistentes a fagos.

Na pesquisa de Cabrera et al. (2000), 10 (dez) amostras de soro de queijo fresco provenientes de plantas locais de fabricação de queijos da Venezuela foram submetidas à deteç̧ão de bacteriófagos; destas amostras, 4 (quatro) foram positivas para fagos. Também foram avaliados os efeitos dos bacteriófagos nas atividades fermentativas de culturas de Enterecoccus faecalis e de Lactobacillus casei. Segundo os autores, a atividade fermentativa dessas cepas de bactérias ácido-láticas foi afetada pela presença dos bacteriófagos, sendo o $L$. casei mais susceptível do que o $E$. faecalis.

Em um estudo realizado por Szczepańska et al. (2007), em 33 amostras de soro oriundas de laticínios da Polônia foram avaliadas quanto à presença de fagos específicos para Lactococcus lactis. De acordo com os autores, todas as amostras

\section{Referências}

AMERICAN PUBLIC HEALTH ASSOCIATION. Committee on Microbiologycal Methods for Foods. Compendiun of Methods for the Microbiologycal Examination of Foods. Washington, APHA, 2001. 129 p.

ANTUNES, A.J. Funcionalidade de proteínas do soro de leite bovino. Barueri, Manole, 2003. 135 p.

BARBOSA, A.S.; ARAÚJO, A.S.; FLORÊNCIA, I.M.; BEZERRA, R.R.A.; FLORENTINO, E.R. Estudo cinético da fermentação do soro de queijo de coalho para produção de aguardente. Revista Verde, v.5, n.3, p. 237-254, 2010. estavam contaminadas com fagos, constituindo-se um sério problema tecnológico nos laticínios poloneses.

Lima et al. (2009) pesquisaram bacteriófagos específicos para Escherichia coli em 12 amostras de leite, soro e queijo de coalho de unidades de processamento de queijo de coalho do Ceará. Detectaram a presença de fagos em apenas duas amostras de soro oriundas de processamento artesanal, o que possivelmente pode estar relacionado com a higienização e manipulação durante a produção.

Em relação à presença de resíduos de antimicrobianos, foi detectada positividade em 17 amostras de soro (34\%); negatividade em 15 amostras (30\%) e as 18 amostras (36\%) restantes apresentou-se no limite máximo permitido de resíduos de antibióticos.

A presença de resíduos de antibiótico é um indicativo do uso indiscriminado de drogas no tratamento animal ou do não cumprimento do prazo de carência dos medicamentos, impossibilitando o uso deste soro pela indústria e podendo ainda causar danos aos consumidores (Cortez e Cortez 2008).

No trabalho descrito por Campos et al. (2006) em queijos Minas Frescal, foram isoladas 25 cepas de E. coli. Observou-se resistência $(4,0 \%)$ à ampicilina, ao sulfametoxazol- trimetoprim e à tetraciclina e susceptibilidade aos cefalotina, gentamicina, ciprofloxacina. No estudo de Franco et al. (2010) cepas de Escherichia coli patogênicas apresentaram resistência a sete antibióticos usados rotineiramente no tratamento das enfermidades transmitidas por alimentos e foram sensíveis apenas à gentamicina e à tobramicina.

Sabe-se que a administração de quantidades subterapêuticas de antimicrobianos ocasiona um aumento na frequência de bactérias resistentes, tanto no homem quanto nos animais. Trabalhos relatam a resistência de bactérias patogênicas frente aos antibióticos. O S. aureus mostrou resistência à penicilina, ampicilina e tetraciclina em estudos conduzidos por Brito et al. (2001) e Rapini et al. (2004).

\section{Conclusões}

O controle da qualidade do soro nas indústrias garante um produto inócuo à saúde do consumidor. A contagem bacteriana apresentou valor significativo, o que pode comprometer os derivados lácteos, principalmente no que diz respeito à contagem de psicrotróficos que apontou valor superior ao determinado por lei. A ausência de fagos é um ponto positivo nas indústrias. A presença de antimicrobianos é um ponto preocupante em saúde pública, tendo em vista os problemas ocasionados ao ser humano.

BONFOH, B.; WASEM, A.; TRAORE, A.N.; FANE, A.; SPILLMANN, $\mathrm{H}$. Microbiological quality of cow's milk taken at different intervals from the udder to selling point in Bamako (Mali). Food Control, v.14, n.7, p.495-500, 2003.

BRASIL. Ministério da Agricultura, Pecuária e Abastecimento. Regulamento da Inspeção Industrial e Sanitária de Produtos de Origem Animal, aprovado pelo Decreto $n^{\circ} 30.691$ de 29/03/52, alterado pelos Decretos $n^{\circ} 1.255$ de 25/06/62, 1.236 de 02/09/94, 1.812 de 08/02/96 e $n^{\circ} 2.244$ de 04/06/97, Brasília, Distrito Federal - DF. 2008.

BRITO, M.A.V.P. Resíduos de antimicrobianos no leite. Juiz de Fora: Embrapa Gado de Leite, 2000.28p. Circular técnica 60. 
BRITO, M.A.V.P.; BRITO, J.R.F.; SILVA, M.A.S; CARMO, R.A. Concentração mínima inibitória de dez antimicrobianos para amostras de Staphylococcus aureus isoladas de infecção intramamária bovina. Arquivo Brasileiro Medicina Veterinaria Zootecnia, v.53, n.5, p.531-537, 2001.

CABRERA, L.; FERRER, A.; RODRÍGUEZ, G.O. Susceptibility of Enterococcus faecalis and Lactobacillus casei strains isolated from palmita-type Venezuelan cheese to bacteriophages. Revista Científica FCV-Luz, v.10, n.5, p.417-422, 2000.

CAMPOS, M.R.H.; KIPNIS,A.;ANDRÉ, M.C.D.P.B.; VIEIRA, C.A.S.; JAYME, L.B.; SANTOS, P.P.; SERAFINI, A.B. Caracterização fenotípica pelo antibiograma de cepas de Escherichia coli isoladas de manipuladores, de leite cru e de queijo "Minas Frescal" em um laticínio de Goiás, Brasil. Ciência Rural, v.36, n.4, p.1221-1227, 2006.

CHEHADI, M.C.G.; VIEIRA, J.A.G. Comportamento reológico do soro de queijo. Revista Instituto Laticínios Candido Tostes, v.59, n.339, p.169-172, 2004.

CHIAPPINI, C.C.J.; FRANCO, R.M.; OLIVEIRA, L.A.T. Avaliação do soro de queijo quanto aos coliformes totais e coliformes fecais. Revista Instituto Laticínios Candido Tostes, v.50, p.253-257, 1995. CORTEZ, M.A.S.; CORTEZ, N.M.S. Qualidade do leite: Boas Práticas Agropecuárias e Ordenha Higiênica. Niterói, Editora Universidade Federal Fluminense, 2008. 75p.

CORTEZ, M.A.S.; CORTEZ, N.M.S. Derivados lácteos fermentados e queijos maturados. Editora São Paulo: Instituto Grupo Pão de Açúcar, 2010. 82 p.

COSTA, E.O. Resíduos de antibióticos no leite: um risco à saúde do consumidor. Higiene Alimentar, São Paulo, v.10, n.44, p.15-17, 1996.

DENOBILE, M.; NASCIMENTO, E.S.Validação de método para determinação de resíduos dos antibióticos oxitetraciclina, tetraciclina, clortetraciclina e doxiciclina, em leite, por cromatografia líquida de alta eficiência. Revista Brasileira de Ciências Farmacêuticas, v.40, n.2, 2004.

FOX, P.F.; GUINEE, T.P.; Cogan T.M. \& Mcsweeney P.L.H. Fundamentals of cheese science. Gaithersburg: Aspen Publishers, 2000. 587p.

FRANCO, R.M.; MANTILA, S.P.S. Enumeração e Identificação de Enterococcus spp e Cepas de E. coli Patogênicas em Coxas de Frango e Estudo da Atividade Antimicrobiana das Cepas Isoladas. XV Seminário de Iniciação Científica e Prêmio UFF - Vasconcellos Torres de Ciência e Tecnologia, 07-11/11/2005. CD

FRANCO, R.M.; MANTILLA, S.P.S.; GOUVÊA, R.; OLIVEIRA, L.A.T. Resistência antimicrobiana de Escherichia coli isoladas de carne e dejetos suínos. Acta Veterinaria Brasilica, v.4, n.1, p.31-36, 2010.

FURTADO, M.M.; LOURENÇO NETO, J.P.M. Tecnologia de queijos: manual técnico para a produção industrial de queijos. São Paulo, Dipemar, 1994. 118 p.

HEJNOWICZ, M.S.; BARDOWSKI, J. Bacteriophage infections of mesophilic bacteria in dairy industry. Polish Dairy Journal. v.7, p.2-7, 2005.

LIMA, C.P.; CARVALHO, A.K.F.; BRUNO, L.M.; FIGUEIREDO, E.A.T. Isolamento de bacteriófagos de bactérias láticas da linha de produção de queijos de coalho artesanal e industrial. $25^{\circ}$ Congresso Brasileiro de Microbiologia. Porto de Galinhas - PE. 2009.
MADERA, C.; MONJARDI'N, C.; SUA'REZ, J.E. Milk Contamination and Resistance to Processing Conditions Determine the Fate of Lactococcus lactis Bacteriophages in Dairies. Applied Environmental Microbiology, v.70, n. 12 p. 7365-7371, 2004.

MERCK. Microbiological Manual. Berlin, Germany, 2002. 407p.

NADER FILHO, A.; FERREIRA, L.M.; AMARAL, L.A.; ROSSI JUNIOR, O.D.; PERRY, K.S.P. Queijos: aspectos químicos, bioquímicos e microbiológicos. Química Nova, v.27, n.2, p.293300, 2004.

RAPINI, L.S.; TEIXEIRA, J.P.; MARTINS, N. E.; CERQUEIRA, M.M.O.P.; SOUZA, M.R.; PENNA, F.A.M. Perfil de resistência antimicrobiana de cepas de Staphylococcus $s p$. isoladas de queijo tipo coalho. Arquivo Brasileiro Medicina Veterinaria Zootecnia, v.56, n.1, p.130-133, 2004.

SANTOS, V.A.Q.; HOFFMANN, F.L. Evolução da microbiota contaminante em linha de processamento de queijos Minas frescal e ricota. Revista Instituto Adolfo Lutz, v.69, n.1, p.38-46, 2010.

SISO, M.I.G. The biotechnological utilization of cheese whey: a review. Bioresource Technology, v.57, p.1-11, 1996.

SHITANDI, A.; KIHUMBU, G. Laboratory evaluation of the improved tube test detection limits for $\beta$-lactam residues in Kenyan milk. African Journal of Biotechnology, Nairobi, v. 3, n. 1, p. 82-87, jan. 2004. 20.

SHNEIDER, R.N. Análise microbiológica e do sistema produtivo do queijo serrano produzido no município de Cambará do Sul/RS. Monografia de TCC. Universidade Federal do Rio Grande do Sul, Faculdade de Veterinária, 2009. 60f.

SZCZEPAŃSKA, A.K.; HEJNOWICZ, M.S.; KOŁAKOWSKI, P.; BARDOWSKI, J. Biodiversity of Lactococcus lactis bacteriophages in Polish dairy environment. Acta Biochimica Polonica., v.54, n.1, p.151-158, 2007.

TEIXEIRA, L.V.; FONSECA, L.M.; MENEZES, L.D.M. Avaliação da qualidade microbiológica do soro de queijos Minas padrão e mozarela produzidos em quatro regiões do estado de Minas Gerais. Arquivo Brasileiro Medicina Veterinaria Zootecnia, v.59, n.1, p.264-267, 2007

TENÓRIO, C.G.M.S.C; CERQUEIRA, M.M.O.P; VIEGAS,R.P; RESENDE,M.F.S; CLINQUART,DL; A.K.R; SANTOS,AKR; SOUZA,M.R; PENNA,C.F.A.M. Eficiência dos testes COPAN (Microplate e Single) na detecção de resíduos de antimicrobianos no leite. Arquivo Brasileiro de Medicina Veterinária e Zootecnia, v.61, n.2, p.504-510, 2009.

VAN SCHAIK, G.; LOTEM, M.; SCHUKKEN, Y. H. Trends in somatic cells counts, bacterial counts, and antibiotic residue violations in New York State during 1999-2000. Journal of Dairy Science, Savoy, v. 85, n. 4, p. 782-789, abr. 2002.

ZAFFARI, C.B.; MELLO, J.F.; COSTA, M. Qualidade bacteriológica de queijos artesanais comercializados em estradas do litoral norte do Rio Grande do Sul, Brasil. Ciência Rural, Santa Maria, v. 37, n. 3, p. 862-867, 2007.

ZINK, R.; LOESSNER, M.J. Classification of virulent and temperate bacteriophages of Listeria spp. on the basis of morphology and protein analysis. Applied Environmental Microbiology v. 58, p. 296302. 1992. 